\title{
Gravity wave propagation through a large semidiurnal tide and instabilities in the mesosphere and lower thermosphere during the winter 2003 MaCWAVE rocket campaign
}

\author{
B. P. Williams ${ }^{1}$, D. C. Fritts ${ }^{1}$, C. Y. She ${ }^{2}$, and R. A. Goldberg ${ }^{3}$ \\ ${ }^{1}$ Northwest Research Associates, Colorado Research Associates division, Boulder, Colorado, USA \\ ${ }^{2}$ Department of Physics, Colorado State University, Fort Collins, Colorado, USA \\ ${ }^{3}$ NASA/Goddard Space Flight Center, Laboratory for Solar and Space Physics, Greenbelt, MD, USA
}

Received: 6 October 2005 - Revised: 3 March 2006 - Accepted: 4 May 2006 - Published: 3 July 2006

Part of Special Issue "MaCWAVE: a rocket-lidar-radar program to study the polar mesosphere during summer and winter"

\begin{abstract}
The winter MaCWAVE (Mountain and convective waves ascending vertically) rocket campaign took place in January 2003 at Esrange, Sweden and the ALOMAR observatory in Andenes, Norway. The campaign combined balloon, lidar, radar, and rocket measurements to produce full temperature and wind profiles from the ground to $105 \mathrm{~km}$. This paper will investigate gravity wave propagation in the mesosphere and lower thermosphere using data from the Weber sodium lidar on 28-29 January 2003. A very large semidiurnal tide was present in the zonal wind above $80 \mathrm{~km}$ that grew to a $90 \mathrm{~m} / \mathrm{s}$ amplitude at $100 \mathrm{~km}$. The superposition of smaller-scale gravity waves and the tide caused small regions of possible convective or shear instabilities to form along the downward progressing phase fronts of the tide. The gravity waves had periods ranging from the Nyquist period of $30 \mathrm{~min}$ up to $4 \mathrm{~h}$, vertical wavelengths ranging from $7 \mathrm{~km}$ to more than $20 \mathrm{~km}$, and the frequency spectra had the expected $-5 / 3$ slope. The dominant gravity waves had long vertical wavelengths and experienced rapid downward phase progression. The gravity wave variance grew exponentially with height up from 86 to $94 \mathrm{~km}$, consistent with the measured scale height, suggesting that the waves were not dissipated strongly by the tidal gradients and resulting unstable regions in this altitude range.
\end{abstract}

Keywords. Meteorology and atmospheric dynamics (Middle atmosphere dynamics; Waves and tides; Thermospheric dynamics)

Correspondence to: B. P. Williams

(biff@cora.nwra.com)

\section{Introduction}

The MaCWAVE winter campaign in January 2003 involved 2 sounding rockets and 46 MET rockets launched from ESRANGE, Sweden, 51 balloons launched from ESRANGE and Andoya Rocket Range/ALOMAR, Norway, and radar and lidar data collection at both locations. An overview the campaign is given by Goldberg et al. (2006) and the conditions in the stratosphere are provided by Blum et al. (2006). Mountain waves were present during the first winter salvo (24 January 2003) below $\sim 65 \mathrm{~km}$, but were prevented from penetrating to higher altitudes by a zonal wind reversal due to a stratospheric warming (Wang et al., 2006). A second rocket sequence on 28-29 January 2003 observed a large amplitude semidiurnal variation and superposed high-frequency motions also observed with lidar and radar instrumentation at ESRANGE and ARR/ALOMAR. This paper will concentrate on the amplified semidiurnal tide on 28-29 January 2003 , the resultant regions of possible instability, and the residual gravity wave (GW) field.

\section{Instrumentation}

In 2000, CSU and NWRA/CoRA installed the Weber windtemperature sodium lidar at the ALOMAR observatory in Northern Norway. The lidar measures temperature, radial wind, and sodium density from roughly 80 to $105 \mathrm{~km}$ altitude by probing the Doppler width and Doppler shift of the atmospheric sodium resonance line (She et al., 2002). The Weber lidar uses a unique continuous-wave sum-frequency seed laser and an acousto-optic modulator to generate three

Published by Copernicus GmbH on behalf of the European Geosciences Union. 
highly stabilized seed frequencies at the sodium $\mathrm{D}_{2 a}$ peak and $\pm 630 \mathrm{MHz}$. The seed beam is combined with a pulsed YAG beam in the pulse dye amplifier to obtain typically $1 \mathrm{~W}$ of pulsed power at $589 \mathrm{~nm}$. The Weber lidar splits the pulse output into two beams and receives the backscattered signal using the two 1.8-m diameter telescopes of the ALOMAR Rayleigh/Mie/Raman lidar. For the MaCWAVE/MIDAS winter campaign, the two beams were inclined $20^{\circ}$ to the east and west of zenith in an attempt to measure momentum flux, so meridional winds were not measured with the lidar. The seed laser was running at $10 \%$ of normal power which led to a pulse power of $200 \mathrm{~mW}$ per beam ( $40 \%$ of normal), so we did not have sufficient returned photon counts to calculate momentum flux. The vertical and temporal resolutions that may be deduced from lidar signal were $150 \mathrm{~m}$ and $1 \mathrm{~min}$ for the sodium density and 1 or $2 \mathrm{~km}$ and $15 \mathrm{~min}$ for temperature and winds.

The laser frequency drifted with time during the first $3 \mathrm{~h}$ of the campaign on 28 January 2003, due to operator error. By using the average of the zonal winds in two beams, we can remove the effect of the frequency drift and any vertical wind present from our calculated zonal winds:

$\mathrm{W}_{\mathrm{E}}=\left(\mathrm{V}_{20 \mathrm{E}}-\mathrm{V}_{20 \mathrm{~W}}\right) / 2 \sin \left(20^{\circ}\right)$,

where the radial winds $\left(\mathrm{V}_{20 \mathrm{E}, \mathrm{W}}\right)$ are the sum of the projection of the zonal wind, the projection of the vertical wind, and wind error from the frequency offset. The average removes the effect of the frequency offset and any vertical winds that are the same at the 2 beam locations. The vertical wind is generally 1-2 orders of magnitude smaller than the horizontal wind in a 15-min average, so it is not a big effect in this case. Averaging the two beams can also introduce biases due to small horizontal-scale GWs, but this is also a small effect for averaged data.

\section{Semidiurnal tide}

The lidar data on the night of 28/29 January 2003 were dominated by the semidiurnal tide. Figure 1 shows the effects of the tide on the temperature, zonal wind, and sodium density calculated from the average of both beams. Other waves were visible, however, especially in the temperature and sodium density. The time series of temperature and zonal wind and their errors for both beams at four altitudes are plotted in Fig. 2. The differences between the two zonal wind measurements at the start of the night were due to the laser frequency drift. The temperature was much less sensitive to the frequency drift. Averaging both beams, the zonal wind followed the 12-h fit (black line) quite closely. The temperature fits were quite good for 85 and $90 \mathrm{~km}$, but at higher altitudes the apparent period in the temperature time series was 6 to $8 \mathrm{~h}$, suggesting either a superposition of the semidiurnal tide and shorter-period gravity waves or simply a transition to a 6 or 8 -h tide or GW at these higher altitudes. Earlier in the campaign (25-27 January 2003), there was a significant terdiurnal amplitude in the meteor radar winds, but this was at a lower altitude of $\sim 88 \mathrm{~km}$ (Goldberg et al., 2006). There were also a number of shorter-period perturbations that were present in both beams, indicating a horizontal scale greater than the beam separation of $\sim 60 \mathrm{~km}$.

We fit a 12-h period and a constant term to these times series (Fig. 3). Both tidal theory and the meteor radar measurements of the zonal and meridional wind suggest that the diurnal tide was very small (Goldberg et al., 2006), so the constant term should be very close to the daily mean. The zonal wind semidiurnal amplitude increased from $35 \mathrm{~m} / \mathrm{s}$ at $84 \mathrm{~km}$ to $91 \mathrm{~m} / \mathrm{s}$ at $100 \mathrm{~km}$. The zonal wind phase shows smooth downward progression with time consistent with a $30-\mathrm{km}$ vertical wavelength. The temperature amplitude decays with altitude with a maximum of $14 \mathrm{~K}$ at $84 \mathrm{~km}$ to a minimum of $3 \mathrm{~K}$ at $96 \mathrm{~km}$. The temperature phase has the expected quadrature with the zonal wind phase (a 3-h lag) for a westward-propagating tide. The derived temperature phase becomes in phase with the zonal wind at higher altitudes, but the temperature fit is not good at higher altitudes as the temperature amplitude decays, and there are other indications of wave superposition at higher altitudes, as noted above.

The tidal signal also showed up in both the meteor radar and the falling sphere measurements. The zonal wind amplitudes measured by the meteor radar were also quite large, although about $10 \%$ lower than the lidar amplitudes. The falling sphere temperatures and zonal winds also agreed well with the lidar data, although the falling spheres only measured up to about $85 \mathrm{~km}$ over a period of $6 \mathrm{~h}$ (Goldberg et al., 2006).

We have not identified the specific cause for the zonal wind amplitude to increase so strongly while the temperature amplitude decays with altitude. Dissipation can affect the structure of the tide and change the relationship between the vertical wind (and resulting temperature perturbation) and the horizontal winds, but cannot account for the apparent change in period. Meteor radar measurements show similar meridional amplitudes that increase with height on this night, indicating that the tidal winds had a normal spiral structure and suggesting a fairly simple modal structure.

The mean temperature profile decreases slightly with height from $210 \mathrm{~K}$ at $85 \mathrm{~km}$ to $200 \mathrm{~K}$ at $100 \mathrm{~km}$. This is consistent with the expected high winter mesopause, but the mean gradient is quite small at only $0.67 \mathrm{~K} / \mathrm{km}$. The mean zonal wind profile varies from $-10 \mathrm{~m} / \mathrm{s}$ at $85 \mathrm{~km}$ to $30 \mathrm{~m} / \mathrm{s}$ at $100 \mathrm{~km}$. This represents a moderate positive altitude gradient of $\sim 2.7 \mathrm{~m} / \mathrm{s} / \mathrm{km}$. These mean gradients are much smaller than the tidally-induced gradients.

\section{Instabilities}

The principal instabilities accompanying GWs and winds shears in the atmosphere are generally considered to be 

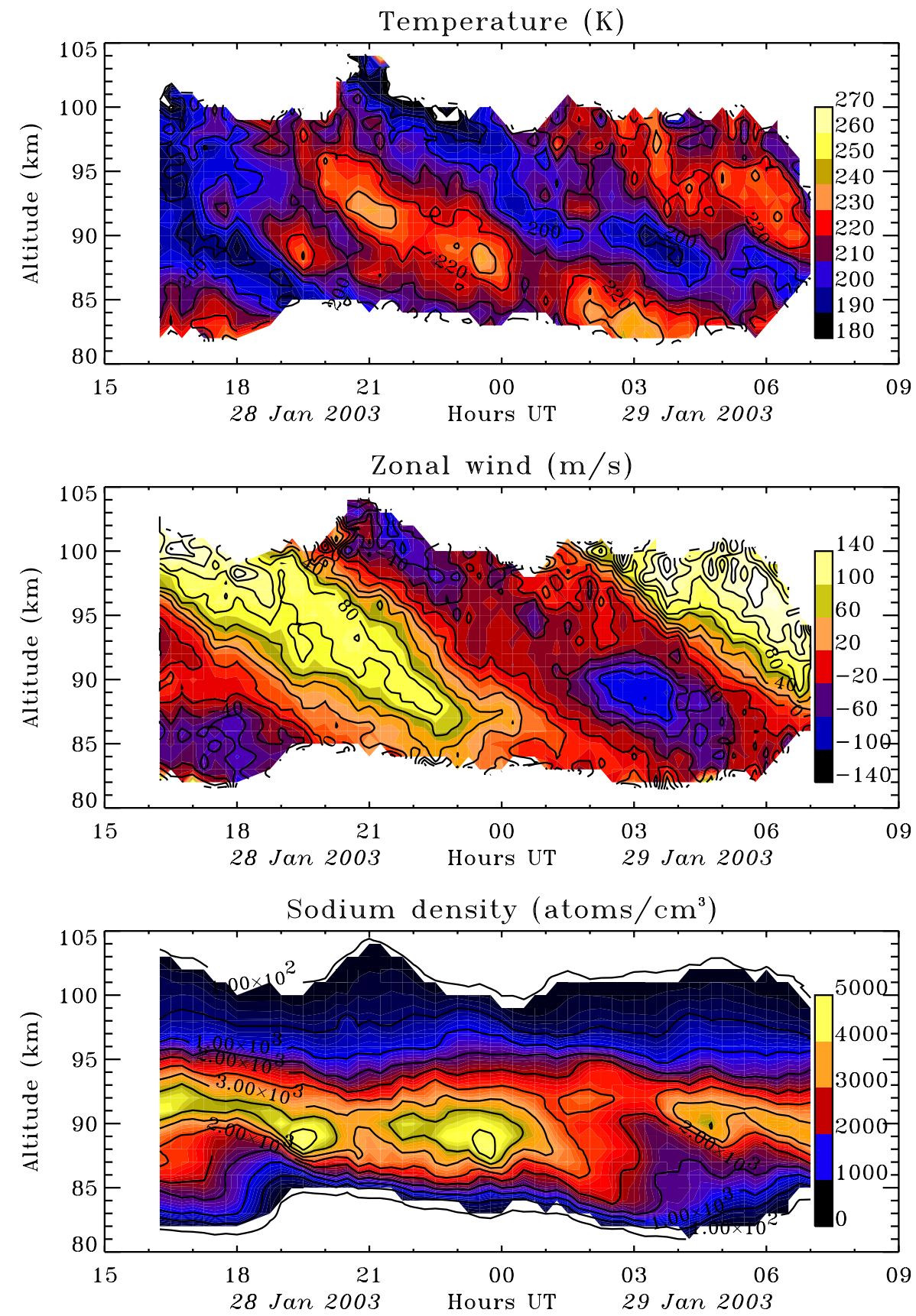

Fig. 1. Contours of temperature, zonal wind, and sodium density for 28-29 January 2003 measured by the Weber lidar using the average of the two beams. Note the strong semidiurnal perturbation.

convective or dynamical in nature. This proves to be a significant (and inaccurate) simplification, in general, as there are a multitude of instabilities that can arise, and these depend on the specific characteristics of the flow, the amplitudes and intrinsic properties of the involved waves, the initial conditions at the time of instability occurrence, and the influences of viscosity and thermal diffusivity (Achatz, 2005; Fritts et al., 2006; Lombard and Riley, 1996; Sonmor and
Klaassen, 1997; also see Fritts and Alexander, 2003, for a review of these dynamics). Despite this complexity, the simpler view of these instabilities often provides a convenient and qualitative, if imperfect, context in which to assess instability structures, energetic sources, and occurrence. Given this (and because we cannot assess initial conditions and specific details in each case), we assume that convective instability can occur when the temperature lapse rate $(-\mathrm{d} T / \mathrm{d} z)$ is 

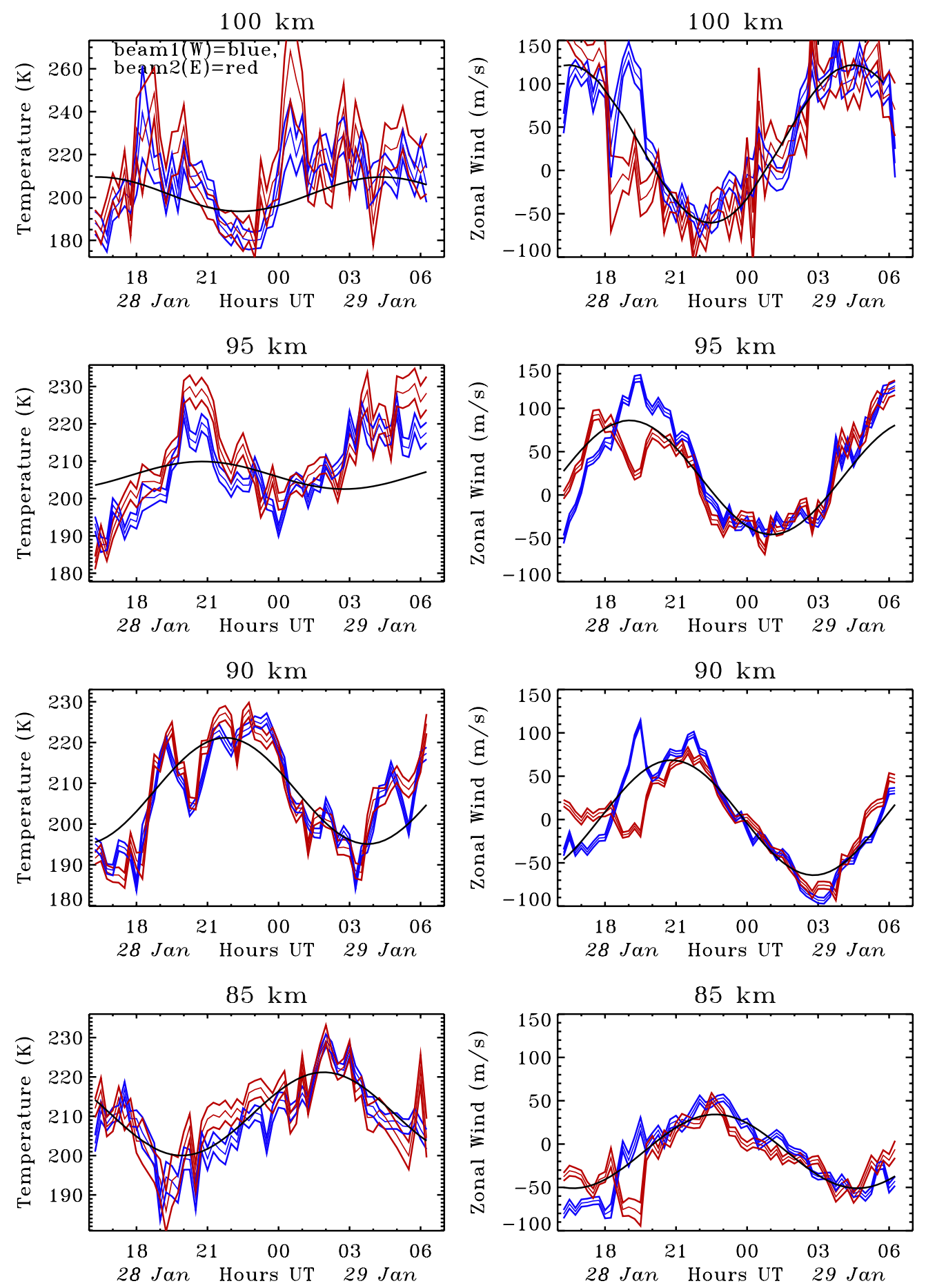

Fig. 2. Time series of zonal wind (right column) and temperature (left column) for beam 1 (20W, blue) and beam 2 (20E, red) for 4 altitudes with errors and the semidiurnal fit (black line).

greater than the adiabatic lapse rate of $9.5 \mathrm{~K} / \mathrm{km}$, resulting in an imaginary buoyancy frequency, $N$. Dynamical instability is assumed to be caused by large wind shears and to occur when the Richardson number $(R i)$ is less than 0.25 . Taking the simple view, we calculate the temperature gradient and buoyancy frequency from the temperature profile for each beam and for the average of the two beams. The Richardson number is defined as the buoyancy frequency squared divided by the square of the vertical shear of the horizontal wind. We also will use only the zonal wind gradient (as the 

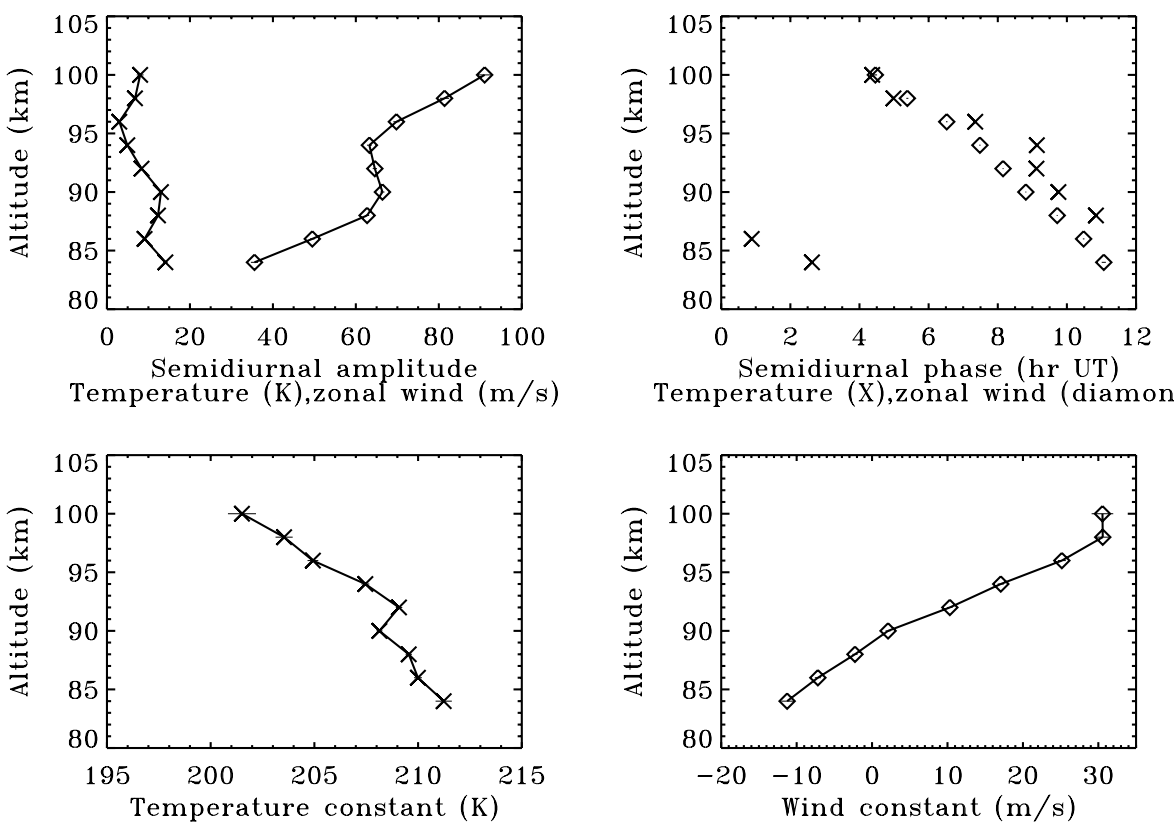

Fig. 3. Semidiurnal amplitude, phase, and constant for zonal wind and temperature on 28 January 2003. Note how the zonal wind amplitude increases with height and the temperature amplitude decreases with height. The phase difference between zonal wind and temperature goes from over $3 \mathrm{~h}$ at $84 \mathrm{~km}$ to near zero above $95 \mathrm{~km}$. The mean wind and temperature profiles have a simple structure and relatively small gradients.

lidar measured only in the zonal plane), which will underestimate the total wind shear and overestimate $R i$. Figure 4 shows the regions where $R i$ is less than 0.25 and the temperature gradient is more negative than $-9.5 \mathrm{~K} / \mathrm{km}$, the adiabatic gradient for this altitude. There was a broad region of instability following the downward phase progression of the tide, as well as additional descending zones of instability due to a 4-h wave during the first half of the night. Within each region, there were small patches of potential instability where smaller-scale waves enhanced the gradients due to the longer-period waves beyond the identified thresholds. The small patches sometimes occur in both beams at the same time and show up in the average $\mathrm{d} T / \mathrm{d} z$, but most often the two beams are different, which is not surprising given the horizontal separation of the beams and the small-scales of the perturbing GWs. To summarize, it appears that the semidiurnal tide and longer-period GWs push the gradients close to instability, and that scattered smaller-scale unstable regions are induced by small-scale GWs.

\section{Gravity waves}

We have looked at the semidiurnal tide and investigated the conditions for instability on this night. We will now look at the smaller-scale GWs and see whether their propagation was affected by the large and variable gradients present on this night.
We first subtracted the fitted semidiurnal tide from the temperature and wind fields calculated from the average of the two beams. These residual fields are shown in Fig. 5 along with the error values. There are many perturbations visible with amplitude larger than the noise level. Most of the perturbations were present in both temperature and zonal wind and showed coherence in altitude and downward phase propagation consistent with upward propagating GWs. There were a number of waves with periods from 30-60 min and long vertical wavelengths, as well as the 4-h wave evident in Fig. 4. There are relatively few GWs with vertical wavelengths less than $7 \mathrm{~km}$. Lomb periodograms were computed from the residual time series of temperature and wind and are displayed in Fig. 6. The spectra are fairly broad, given the limited data set, and generally followed the expected $-5 / 3$ slope. The variances of the residual temperature and zonal wind both increased strongly (by about a factor of 5) from 86 to $94 \mathrm{~km}$ (see Fig. 7). The scale height was $6.1 \mathrm{~km}$ for the mean temperature on this night of $205 \mathrm{~K}$. Thus we would expect a factor of four increase in the variance for undamped GWs propagating $8 \mathrm{~km}$ vertically. This is consistent with largely undamped vertical wave propagation, in the absence of any local GW sources. One complication is that regions of wave breaking and instability are expected to produce secondary waves (Vadas et al., 2003). These secondary waves would propagate both upwards and downwards, but upward propagation dominates in this dataset. So it appears that even though there were many scattered regions with conditions 

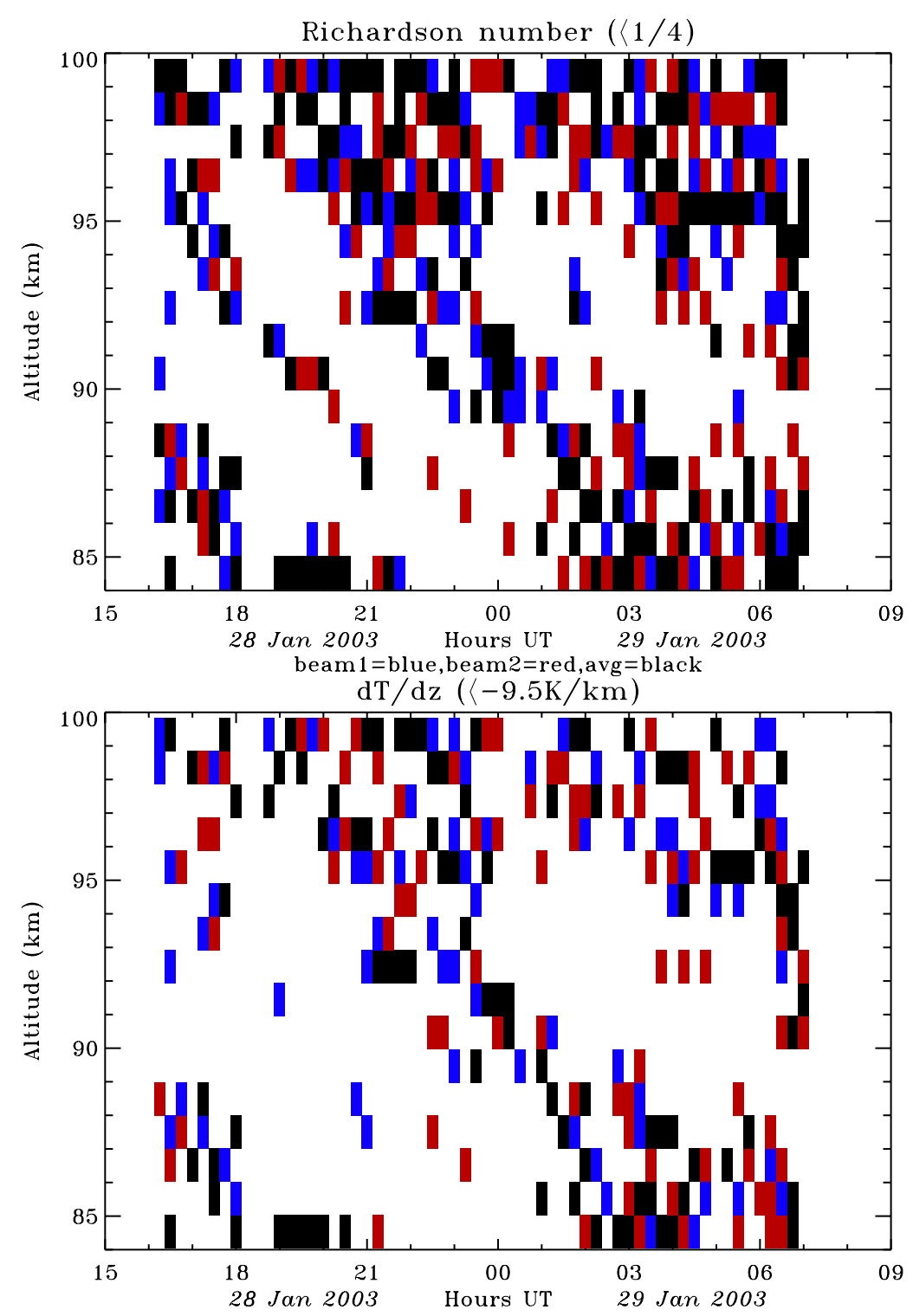

Fig. 4. Regions where the Richardson number is less than 1/4(top) or the lapse rate is greater than adiabatic (bottom) using the temperature gradient for beam 1 (blue), beam 2 (red), and the average of the two beams (black).

suitable for instability, the GWs were not affected and increased essentially undamped in amplitude up to $\sim 95 \mathrm{~km}$. One reason may be that the vertical wavelengths of the waves were typically much larger than the unstable regions. There were shorter vertical wavelength waves in the falling sphere data from 45 to $65 \mathrm{~km}$ but these do not appear to have propagated into the mesopause region (Wang et al., 2006)

\section{Discussion and conclusions}

During the rocket campaign on 28-29 January, we observed simultaneously an amplified zonal wind semidiurnal tide leading to regions of instability descending with the tidal phase, enhanced turbulent energy dissipation rates, and enhanced gravity wave variance. The tides were quite active and variable during the campaign period. The zonal wind amplitude of the semidiurnal tide was unusually strong $(85 \mathrm{~m} / \mathrm{s})$ on 28 January 2003 , but the temperature amplitude was not as enhanced. The Andoya meteor radar measured a $30 \mathrm{~m} / \mathrm{s}$ amplitude 8-h wave from 25-27 January 2003 at 88$\mathrm{km}$ altitude, possibly a terdiurnal tide. At higher altitudes, the semidiurnal tide was larger than the 8 -h wave. The semidiurnal zonal wind amplitude at $88 \mathrm{~km}$ increased to a $60 \mathrm{~m} / \mathrm{s}$ average from 28-30 January then decreased to a more typical $20 \mathrm{~m} / \mathrm{s}$ by 31 January (Goldberg et al., 2006). 

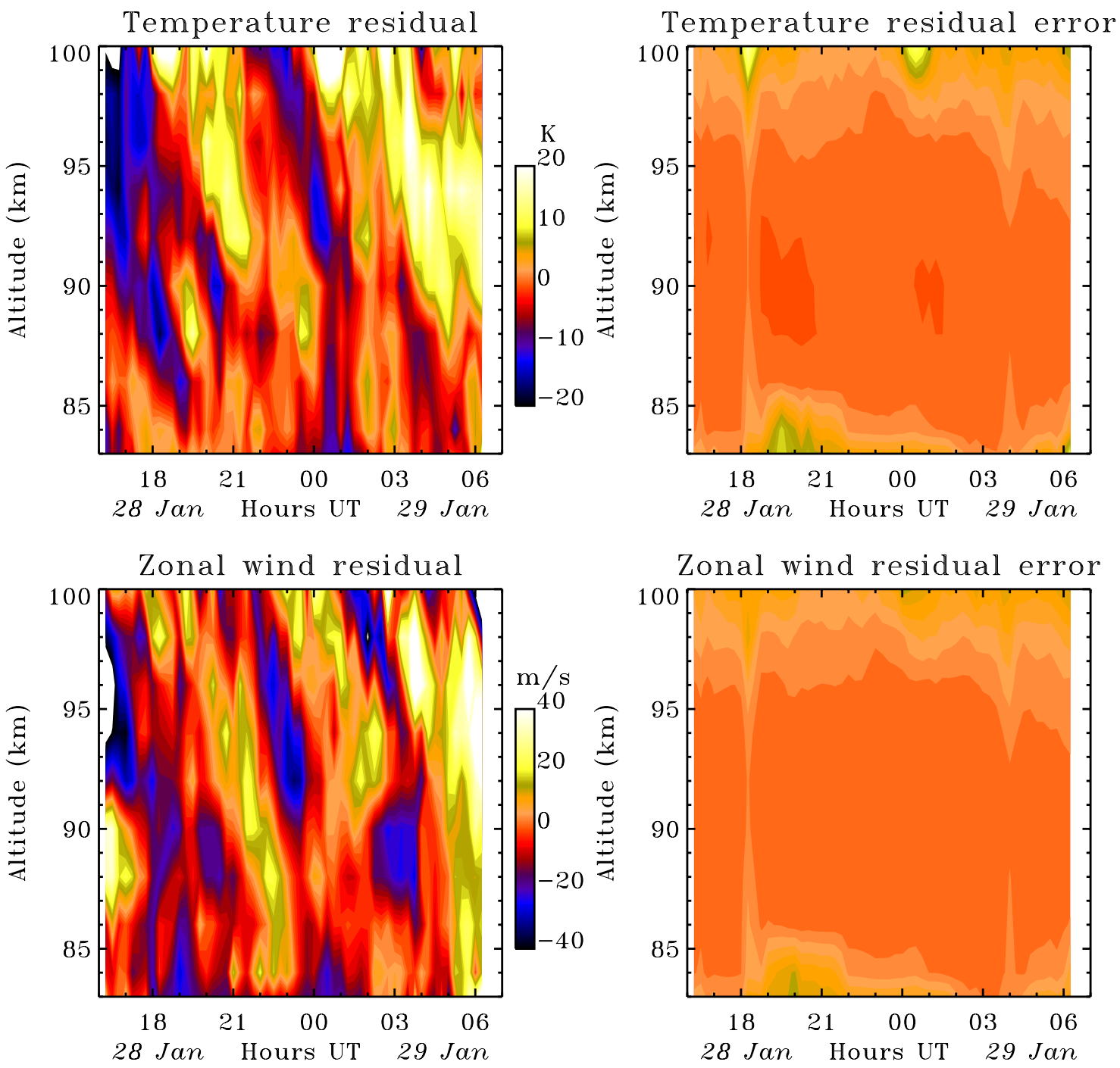

Fig. 5. Contour plots of the residual wind and temperature fields after subtracting the semidiurnal fit. Note the many perturbations larger than the errors (shown on the right) with mostly downward phase propagation.

The MaCWAVE Terrier-Orion rocket was launched at 18.5 UT and measured turbulent energy dissipation rates from 75 to $90 \mathrm{~km}$ that were significantly larger than normal for wintertime conditions at $\sim 100 \mathrm{~mW} / \mathrm{kg}$, but not as large as some of the summertime measurements (Croskey et al., 2006). The rocket measurements were made just after the downward-moving potentially-unstable region in the bottom left corner of Fig. 4. This delay is consistent with gravity waves breaking in the unstable region, leading to turbulence 1-2 buoyancy periods later, but the lidar did not have the necessary time resolution to directly measure this. The gravity wave variance increased with height from $\sim 85$ to $95 \mathrm{~km}$, however, so the average dissipation throughout the night may not have been as significant. Also, much of the energy dissipation may have come from waves at periods less than the 30 min Nyquist period. Previous rocket campaigns have gen- erally measured higher energy dissipation rates in mesopause region in the summer than in the winter (Lubken, 1997).

The gravity wave spectrum was broad and covered the full frequency range that we could measure. The GWs appeared to propagate upwards without significant damping, even in the presence of unusually large tide-induced wind and temperature shears. The semidiurnal tide amplitude increased with height in the zonal and meridional wind but decreased in temperature. The GW wave field is more active than expected for the winter polar regions, though relatively few measurements of wind and temperature with this spatial and temporal resolution have been made to date. Hansen and Hoppe (1996) made lidar and incoherent scatter radar measurements in late summer that showed an active gravity wave field and semidiurnal tide that are damped by the gradients below the low summer mesopause leading to turbulence. 

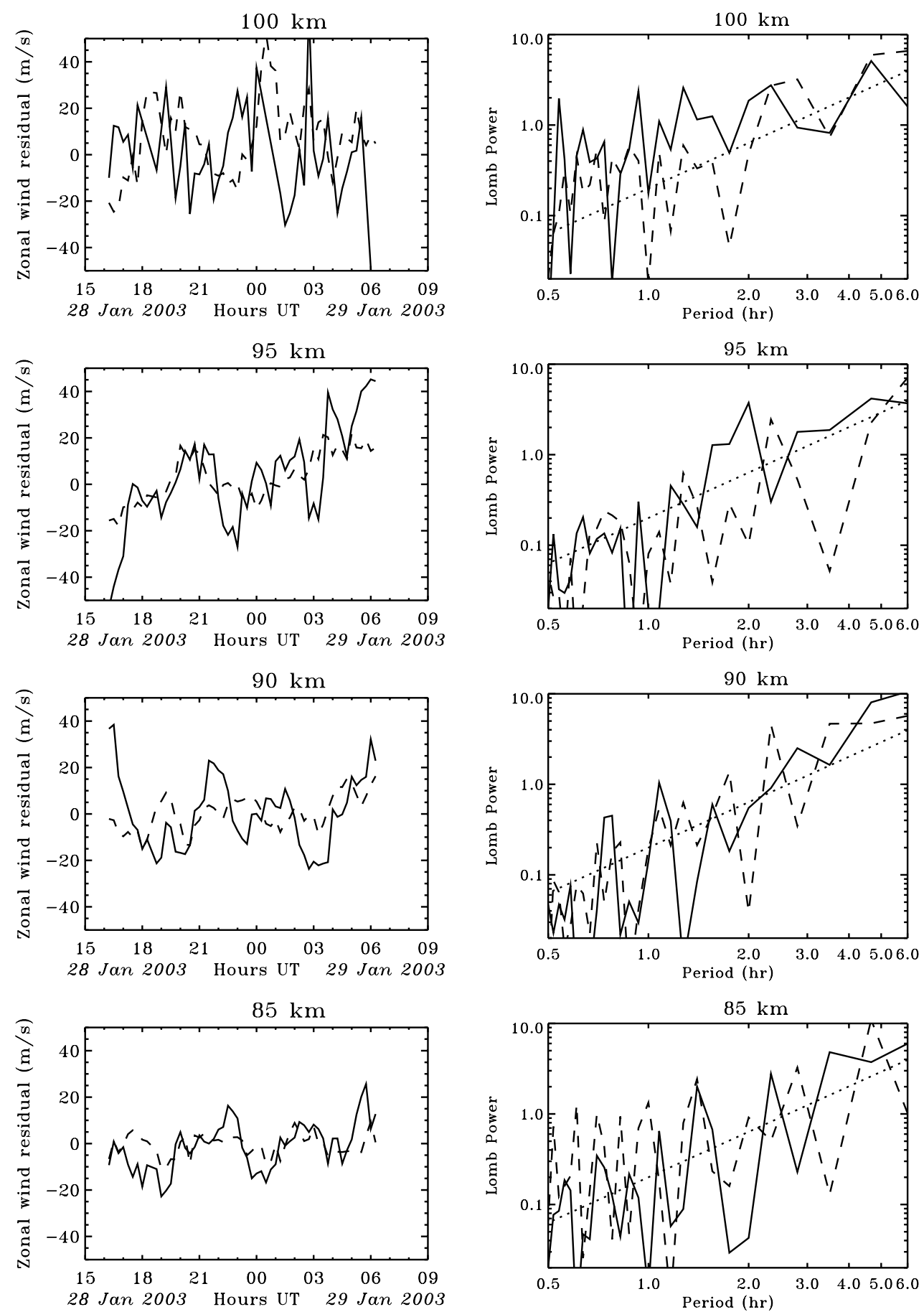

Fig. 6. Left column: Residual temperature (dash) and zonal wind (solid) perturbations after subtraction of semidiurnal tide. Right column: Lomb spectra for zonal wind (solid) and temperature (dash) residual and dotted line indicating a $-5 / 3$ slope.

Collins and Smith (2004) report damping of long-period gravity waves measured by sodium lidar and $\mathrm{OH}$ spectrometer over Alaska by convective instabilities likely produced by the superposition of long and short period waves.

High-resolution instability studies have been done at midlatitudes at Starfire, New Mexico and Maui, Hawaii by the
University of Illinois sodium lidar group (Liu et al., 2004, 2005; Zhao et al., 2003). Liu et al. (2004) described layers of likely convective instability caused by a large diurnal tide, in a similar fashion as the semidiurnal tide dominant at ALOMAR. Zhao et al. (2003) found that the "probabilities of static and dynamic instabilities are maximum in mid-winter" 


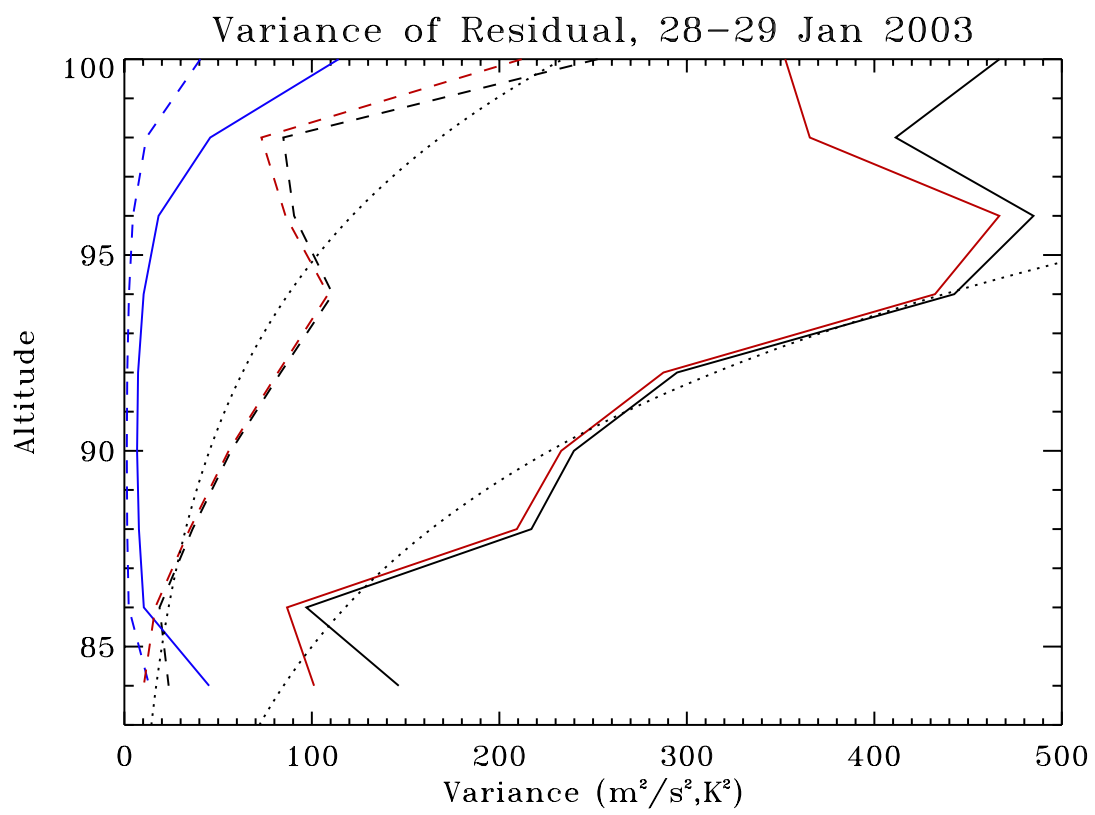

Fig. 7. The variance of the residual temperature (dashed) and wind (solid) fields increases strongly with altitude from 86 to $96 \mathrm{~km}$. Below $86 \mathrm{~km}$ and above $96 \mathrm{~km}$, the instrument mean square error (blue lines) increases rapidly, so it is subtracted from total variance to give the red lines, but do not put much weight in the top or bottom points, as they depend on an accurate error estimate. The dotted lines show the growth rate for an undamped wave.

and that the "structure of the unstable regions are significantly influenced by atmospheric tides". Li et al. (2005) investigated the relationship between the temperature and wind gradients and concluded that a simple tide could not explain the observations. This is consistent with the complicated nature of the semidiurnal perturbation observed at ALOMAR, where the temperature and wind amplitudes change differently with height. These mid-latitude papers did not report the effect of the unstable regions on the propagation of smaller-scale gravity waves, however.

More measurements with high resolution in both time and altitude need to be made in the polar regions to understand the vertical propagation and breaking of the shorter-period waves and why they seem to be damped by instabilities in some cases and not in others. We are also proceeding with winter-time momentum flux measurements with the Weber lidar to understand the effect of gravity breaking on the mean flow and polar thermal structure.

Acknowledgements. This work was supported at NWRA/CoRA and CSU in part by AFOSR under contracts F49620-00-C-0008 and F49620-03-C-0045, by NSF under grants ATM-0137354, ATM0137555, and ATM-0436703. We acknowledge the important support of the Andoya Rocket Range and the ALOMAR observatory.

Topical Editor U.-P. Hoppe thanks G. R. Swenson and another referee for their help in evaluating this paper.

\section{References}

Achatz, U.: On the role of optimal perturbations in the instability of monochromatic gravity waves, Phys. of Fluids, 17, 094107, doi:10.1063/1.2046709, 2005.

Blum, U., Baumgarten, G., Schoech, A., Kirkwood, S., Naujokat, B., and Fricke, K. H.: The meteorological background situation in northern Scandinavia during January/February 2003 in the coontext of MaCWAVE campaign, Ann. Geophys., 24, this issue, 2006.

Collins, R. L. and Smith, R. W.: Evidence of damping and overturning of gravity waves in the Arctic mesosphere: $\mathrm{Na}$ lidar and $\mathrm{OH}$ temperature observations, J. Atmos. Sol.-Terr. Phys., 66, 867879, 2004.

Croskey, C. L., Mitchell, J. D., Friedrich, M., Schmidlin, F. J., and Goldberg, R. A.: Langmuir probe observations of electron and ion profiles in the presence of polar mesospheric gravity waves observed during the MaCWAVE program, Ann. Geophys., 24, this issue, 2006.

Fritts, D. C. and Alexander, M. J.: Gravity wave dynamics and effects in the middle atmosphere, Rev. Geophys., 41, 1003, doi:10.1029/2001RG000106, 2003.

Fritts, D. C., Vadas, S. L., Wan, K., and Werne, J. A.: Mean and variable forcing of the middle atmosphere by gravity waves, J. Atmos. Solar-Terres. Phys., 68 247-265 2006.

Goldberg, R. A., Fritts, D. C., Schmidlin, F. J., Williams, B. P., Croskey, C. L., Mitchell, J. D., Friedrich, M., Russell III, J. M., Blum, U., and Fricke, K. H.: The MaCWAVE program to study gravity wave influences on the polar mesosphere, Ann. Geophys., 24, this issue, 2006.

Hansen, G. and Hoppe, U. P.: Investigation of the upper meso- 
spheric dynamics under late polar summer conditions by EISCAT and LIDAR, J. Atmos. Terr. Phys., 58, 317-335, 1996.

Li, F., Liu, A. Z., and Swenson, G. R.: Characteristics of instabilities in the mesopause region over Maui, Hawaii, J. Geophys. Res., 110, D09S12, doi:10.1029/2004JD005097, 2005.

Liu, A. Z., Roble, R. G., Hecht, J. H., Larsen, M. F., and Gardner, C. S.: Unstable layers in the mesopause region observed with $\mathrm{Na}$ lidar during the Turbulent Oxygen Mixing Experiment (TOMEX) campaign, J. Geophys. Res., 109, doi:10.1029/2002JD003056, 2004.

Lombard, P. N. and Riley, J. J.: Instability and breakdown of internal gravity waves .1. Linear stability analysis, Physics of Fluids, 8, 3271-3287, 1996.

Lubken, F. J.: Seasonal variation of turbulent energy dissipation rates at high latitudes as determined by in situ measurements of neutral density fluctuations, J. Geophys. Res., 102, 13441$13456,1997$.
She, C. Y., Vance, J. D., Williams, B. P., Krueger, D. A., Moosmüller, H., Gibson-Wilde, D., and Fritts, D. C.: Lidar studies of atmospheric dynamics near polar mesopause, EOS, 83, 289-293, 2002.

Sonmor, L. J. and Klaassen, G. P.: Toward a unified theory of gravity wave stability, J. Atmos. Sci., 54, 2655-2680, 1997.

Vadas, S. L., Fritts, D. C., and Alexander, M. J.: Mechanism for the generation of secondary waves in wave breaking regions, J. Atmos. Sci., 60, 194-214, 2003.

Wang, L., Fritts, D. C., Williams, B. P., Goldberg, R. A., and Schmidlin, F. J.: Gravity Waves in the Middle Atmosphere during the MaCWAVE Winter Campaign: Evidence of Mountain Wave Critical Level Encounters, Ann. Geophys., 24, this issue, 2006.

Zhao, Y. C., Liu, A. Z., and Gardner, C. S.: Measurements of atmospheric stability in the mesopause region at the Starfire Optical Range, NM, J. Atmos. Sol.-Terr. Phys., 65, 219-232, 2003. 